Fourth International Conference on Sustainable Construction Materials and Technologies http://www.claisse.info/Proceedings.htm

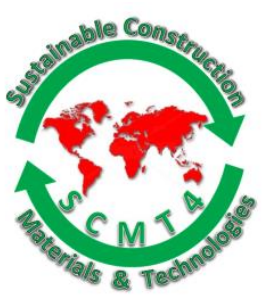

SCMT4

Las Vegas, USA, August 7-11, 2016

\title{
Effect of Recycled Glass Powder and Nanomaterials on the Performance of Concrete
}

\author{
Jessica Flores $^{1 \mathrm{a}}$, Isadora Perdigão Rocha ${ }^{1 \mathrm{~b},}$, Leticia de Sá Carneiro ${ }^{1 \mathrm{c}}$, Karine Pimenta \\ Teixeira $^{1 \mathrm{~d}}$, Mahsa Kamali ${ }^{1 \mathrm{e}}$, Ali Ghahremaninezhad ${ }^{\text {1f }}$
}

${ }^{1}$ Department of Civil, Architectural, and Environmental Engineering, University of Miami, Coral Gables, FL 33134, ${ }^{1 a}$ Email: $<j . f l o r e s 7 @ u m i a m i . e d u>,{ }^{1 b}$ Email: $\langle$ kxp202@miami.edu>,

${ }^{1 c}$ Email: <ixp95@miami.edu>, ${ }^{1 d}$ Email: $\langle l x d 202 @ m i a m i . e d u>$,

${ }^{1 e}$ Email: <m.kamali@umiami.edu>, ${ }^{1 f}$ Email:<a.ghahremani@miami.edu>.

\begin{abstract}
This paper examined the effect of two types of nanoparticles-titanium dioxide $\left(\mathrm{TiO}_{2}\right)$ and montmorillonite (MMT) nanoclay - on the behavior of cement pastes modified with two pozzolanic materials, namely, fly ash (FA) and recycled glass powder (GP). The compressive test was performed to assess the compressive strength; the non-evaporable water content measurement was carried out to study the hydration; and electrical resistivity measurement was conducted to investigate the transport characteristics of the cement pastes. The results indicated that the addition of the nanoparticles improved the compressive strength of the cement paste without GP or FA. It was concluded that the addition of $\mathrm{TiO}_{2}$ nanoparticles resulted in an increased electrical resistivity compared to MMT nanoparticles at late ages. Both $\mathrm{TiO}_{2}$ and $\mathrm{MMT}$ exhibited a similar effect on the hydration of the cement pastes.
\end{abstract}

\section{INTRODUCTION}

The advent of nanotechnology has the potential to revolutionize a wide range of industries including the construction industry. Use of nanomaterials in construction materials is aimed at improving the performance and durability of the construction materials as well as imparting new functionalities to these materials (Sanchez \& Sobolev 2010; Chen \& Poon 2009; Chen et al. 2011; Aly et al. 2011). The improved performance resulting from the use of nanomaterials is primarily due to high surface area of nanomaterials enhancing the chemical and physical processes in construction materials (Sanchez \& Sobolev 2010). The application of $\mathrm{TiO}_{2}$ nanoparticles in construction materials has been studied due to their self-cleaning and air-cleaning properties arising from their photocatalytic characteristic (Chen \& Poon 2009; Chen et al. 2011; Hüsken et al. 2009).

Montmorillonite (MMT) nanoclay belongs to a class of clay called smectite, which comprises a nanoplate structure. Use of MMT in polymer nanocomposites has been extensively studied in the past and shown to improve the physical and mechanical properties of these polymer nanocomposites (Strawhecker \& Manias 2000; Podsiadlo et al. 2007; Prasanth et al. 2013). Prior research has investigated the effect of $\mathrm{TiO}_{2}$ (Lackhoff et al. 2003; Jayapalan et al. 2010; Lee \& Kurtis 2010; Lee \& Kurtis 2013) and MMT (Chang et al. 2007; Hakamy et al. 2015; Aly et al. 2011) on the behavior of cementitious materials. Chang et al. (Chang et al. 2007) indicated that addition of MMT nanoparticles had the potential to increase the 
compressive strength and decrease the permeability of cement paste. They also concluded that the use of MMT nanoparticles resulted in a densification of the microstructure in the cement paste. Aly et al. (Aly et al. 2011) showed that the mechanical properties at 28 days of cement mortars with glass powder and MMT nanoparticles were higher than those of the cement mortars with glass powder. A study by Hakamy et al. (Hakamy et al. 2015) indicated that an increase in the mechanical and thermal properties of cement nanocomposites modified with MMT nanoparticles could result at an optimum dosage. They also highlighted the pozzolanic reactivity of MMT nanoparticles in cementitious materials. Lackhoff et al (Lackhoff et al. 2003) showed an increase in the compressive strength of mortars containing $\mathrm{TiO}_{2}$ nanoparticles. The influence of $\mathrm{TiO}_{2}$ nanoparticles on the hydration of cementitious materials was examined by the researchers (Jayapalan et al. 2010; Lee \& Kurtis 2010) and shown to enhance hydration due to the high surface area of these nanoparticles increasing the nucleation sites for the hydration reaction. Lee et al. (Lee \& Kurtis 2013) reported that compressive strength increased by up to $10 \%$ of $\mathrm{TiO}_{2}$ replacement at low water to cement ratio (0.4) and did not show degradation at high water to cement ratios (0.6).

Although prior studies examined the effect of these nanoparticles on the performance of cement pastes or cement mortars, the effect of these nanoparticles on the behavior of pozzolanic materials has received little attention in the past. This paper aims to study the influence of $\mathrm{TiO}_{2}$ and $\mathrm{MMT}$ nanoparticles on the hydration, mechanical properties, and transport of cementitious materials containing fly ash or glass powder, which possess pozzolanic characteristics (Shayan \& Xu 2006; Kamali \& Ghahremaninezhad 2015). The mechanical properties were assessed using the compressive strength test. Hydration was examined using the non-evaporable water content test. Electrochemical impedance spectroscopy (EIS) was utilized to measure electrical resistivity to study the transport behavior of the cementitious materials.

\section{EXPERIMENTS}

Materials and specimen preparation. In this study, specimens were prepared using Type I Portland cement with the addition of $0.8 \% \mathrm{TiO}_{2}$ and montmorillonite (MMT) nanoparticles and a weight replacement rate of $20 \%$ of glass powder (GP) and a class $\mathrm{F}$ fly ash (FA). The $\mathrm{TiO}_{2}$ nanoparticles (PC105 from CRISTAL $\mathrm{ACTIV}^{\mathrm{TM}}$ ) used in this study was the ultrafine and high purity anatase crystal structure with a surface area of about $90 \mathrm{~m}^{2} / \mathrm{g}$. The MMT nanoparticles (Cloisite $\mathrm{Na}^{+}$from BYK) used in the experiments had a typical median dry particle size of less than $25 \square \mathrm{m}$. Individual MMT nanoparticle is expected to have a thickness on the order of $1 \mathrm{~nm}$ and a planar size on the order of about $\sim 100 \mathrm{~nm}-1000 \mathrm{~nm}$. It should be noted that, agglomeration occurs in both types of nanoparticles if not dispersed properly. GP is a post-consumer byproduct of recycled glass. The physical and chemical properties of GP and FA are given in Table 1.

Table 1. Chemical and physical properties of cement, GP, and FA.

\begin{tabular}{|l|l|l|l|}
\hline Composition(\% by mass) & Cement & FA & GP \\
\hline Silica & 20.6 & 54 & 63.3 \\
\hline Alumina & 4.8 & 28 & 6.4 \\
\hline Iron oxide & 3.5 & 7 & 0.31 \\
\hline Calcium oxide & 64 & 1.4 & 17.1 \\
\hline Magnesium oxide & 0.9 & 1 & 4.5 \\
\hline Sodium oxide & 0.1 & 0.3 & 6.1 \\
\hline Potassium oxide & 0.3 & 2.4 & 0.07 \\
\hline Sulfur trioxide & 3.4 & 0.1 & 0.19 \\
\hline Titanium dioxide & 0.3 & & 0.44 \\
\hline Boron trioxide & & & $0-5$ \\
\hline Median particle size $(\mu \mathrm{m})$ & & 13.1 & 8.4 \\
\hline
\end{tabular}


The nanoparticles were dispersed in water using ultrasonication for $3 \mathrm{~min}$ before adding to the mixture. Cement paste cubes with $25 \mathrm{~mm}$ dimensions at a 0.5 water to binder (cement plus supplementary cementitious material) ratio were prepared in molds of steel and glass. The cubes were cast in two layers, with each layer tamped by a $13 \mathrm{~mm}$ by $25 \mathrm{~mm}$ tamper 32 times. After casting, the cubes were cured in a room with more than $95 \%$ relative humidity and at a temperature of $23 \pm 2{ }^{\circ} \mathrm{C}$ for 24 hours. The cubes were then demolded and stored in a saturated lime solution until testing.

Experimental methods. The effect of $\mathrm{MMT}$ and $\mathrm{TiO}_{2}$ nanoparticles on the behavior of cement pastes with a $20 \%$ replacement of cement with GP and FA was investigated in this study. In order to analyze the influence of the nanoparticles on the properties of the cement pastes modified with these pozzolanic materials, tests related to the measurement of compressive strength, non-evaporable water content, and electrical resistivity of the cubic samples were performed.

Degree of hydration. The non-evaporable water content of the cement pastes was measured at 3 days, 14 days, 28 days, and 91 days of curing. This method is commonly used to evaluate the degree of hydration of cementitious materials (Chen et al. 2012; Hou et al. 2013; Schwarz et al. 2007; Neithalath et al. 2009). A small piece of cement pastes from the center of the cube was ground and passed through the sieve \#60 to achieve about $6 \mathrm{~g}$ of cement paste powder. The powder was dried at $105^{\circ} \mathrm{C}$ for about $24 \mathrm{~h}$ and then ignited for three hours at $1050{ }^{\circ} \mathrm{C}$. The non-evaporable water content was calculated using the following equation:

$W_{n}=\frac{m_{105}-m_{1050}}{m_{1050}}-\left(m_{c} \cdot L O I_{c}+m_{G P, F A} \cdot L O I_{G P, F A}\right)$

where $W_{n}$ is the non-evaporable water content of the paste ( $\mathrm{g} / \mathrm{g}$ binder), $m_{105}$ is the mass of cement paste powder after drying at $105^{\circ} \mathrm{C}(\mathrm{g}), m_{1050}$ is the mass of powder after ignition at $105^{\circ} \mathrm{C}(\mathrm{g}), m_{c}$ is the mass fraction of the cement in binder, $m_{G P, F A}$ is the mass fraction of FA or GP in the cement pastes, $L O I_{c}$ is the loss on ignition of the cement and $L O I_{G P, F A}$ is the loss on ignition of FA or GP. The loss on ignition of cement, FA and GP used in the cement pastes was $2.75 \%, 3.4 \%$, and $0.5 \%$, respectively, according to the manufacturer's specifications.

Compressive strength test. The compressive strength of the cement paste cubes was determined at 3 days, 14 days, 28 days, and 91 days of moisture curing. A SATEC compression machine was used for this test and the maximum compressive load supported by each sample was taken. The average of three identical samples was calculated and reported.

Electrical resistivity test. The electrical resistivity of the cement pastes at 3 days, 14 days, 28 days, and 91 days of curing was measured using EIS. EIS avoids some difficulty prevalent in electrical resistivity measurements using a direct current (DC) arising from charge transfer resistance at the electrodes (Jain \& Neithalath 2010; Neithalath et al. 2006). In the EIS method, the cubes are subjected to an alternating current (AC) with varying frequencies. The imaginary and real parts of the response is used to determine the electrical resistivity of the cement pastes (Snyder et al. 2000). To this end, cement pastes cubes were sandwiched between two metallic plates to serve as electrodes. Two foam pads were soaked in a $1 \mathrm{M} \mathrm{NaCl}$ solution and placed between the specimen ends and plates. A weight was used to compress the whole setup to provide good electrical contact between the specimen and plates. The EIS test was conducted using a Reference Gamry 600 potentiostat/galvanostat with a $250 \mathrm{mV}$ AC current and a frequency range of $10^{6}$ to $10 \mathrm{~Hz}$. The electrical resistivity of the cement pastes cubes was determined as $\square=\left(R-R_{f}\right) A / l$, where $A$ and $l$ are the cross sectional area and thickness of the specimens, respectively, and $R_{f}$ is the electrical resistance of two foam pads. The average electrical resistivity of three identical cubes was calculated and reported. 


\section{RESULTS AND DISCUSSION}

\section{Degree of hydration}

The non-evaporable water content $(\mathrm{Wn})$ of the control cement paste and cement pastes modified with $\mathrm{TiO}_{2}$ and MMT nanoparticles and the cement pastes with the nanoparticles and 20\% replacement of cement with GP and FA are shown in Figure 1a and b. The results at 3 days, 14 days, 28 days, and 91 days of curing are included. In order to allow studying the effect of nanoparticles on the hydration of cement in the cement paste with and without GP and FA, the results were normalized with respect to the cement mass of the cement pastes. It is observed that the cement pastes with $\mathrm{TiO}_{2}$ and MMT nanoparticles showed a lower degree of hydration compared to the control cement paste at 3 days. At 3 days and 28 days the cement pastes with $\mathrm{TiO}_{2}$ and MMT nanoparticles exhibited a similar degree of hydration. A small increase in the degree of hydration of the cement pastes with MMT nanoparticles compared to that of the cement pastes with $\mathrm{TiO}_{2}$ nanoparticles at 14 days can be observed from this figure. It is seen from Figure 1a and b that all cement pastes with GP and FA showed an increased degree of hydration compared to the control cement pastes at 91 days. This is primarily due to the pozzolanic property of GP and FA resulting in more hydration product, especially, at later ages of curing.

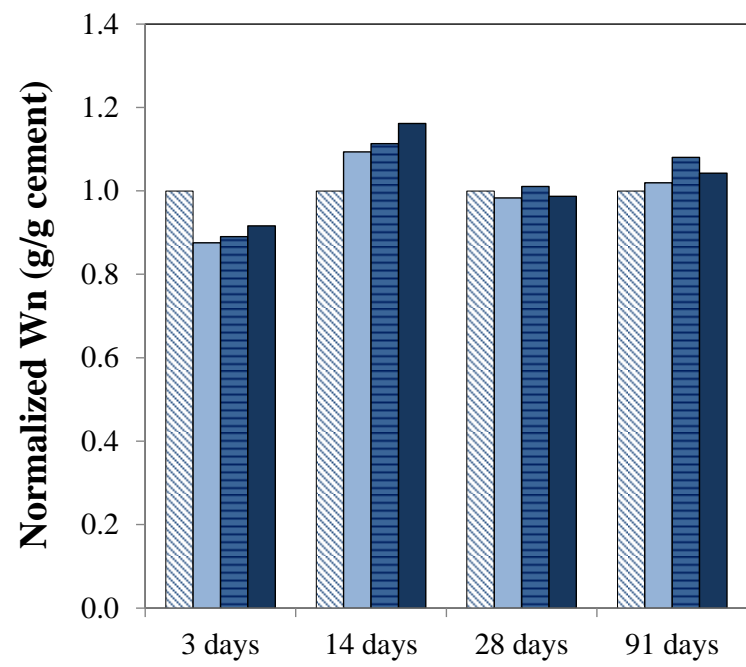

$\otimes$ Control

$\square$ Cement $+0.8 \%$ MMT

$\mathrm{EFA}+0.8 \% \mathrm{MMT}$

$\square \mathrm{GP}+0.8 \% \mathrm{MMT}$

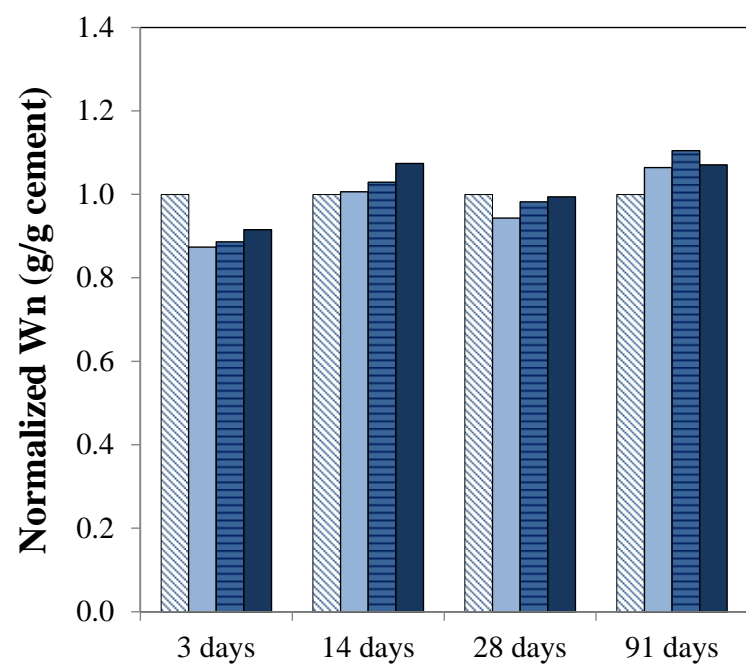

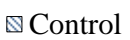

$\square$ Cement $+0.8 \% \mathrm{TiO} 2$

$\mathrm{EFA}+0.8 \% \mathrm{TiO} 2$

$\square \mathrm{GP}+0.8 \% \mathrm{TiO} 2$

Figure 1. Non-evaporable water content of (a) the cement pastes with MMT nanoparticles and (b) the cement pastes with $\mathrm{TiO}_{2}$ nanoparticles at various ages. 


\section{Compressive strength}

The compressive strengths of the cement pastes at 3 days, 14 days, 28 days, and 91 days of curing are shown in Figure 2a and b. It is noted that the addition of $\mathrm{MMT}$ and $\mathrm{TiO}_{2}$ nanoparticles increased the compressive strength of cement paste compared to the control cement paste. It is seen that the cement paste with $\mathrm{TiO}_{2}$ nanoparticles and FA had a higher compressive strength than the cement paste with MMT nanoparticles and FA at all ages studied here. It is observed that MMT nanoparticles increased the compressive strength of the cement paste and the cement paste with GP at 3 days compared to $\mathrm{TiO}_{2}$ nanoparticles; both MMT and $\mathrm{TiO}_{2}$ nanoparticles exhibited a similar influence on the compressive strength of the cement paste and cement paste with GP at 91 days. It is noted that the cement pastes with GP and nanoparticles showed an increase in compressive strength compared to the control cement paste at 91 days.

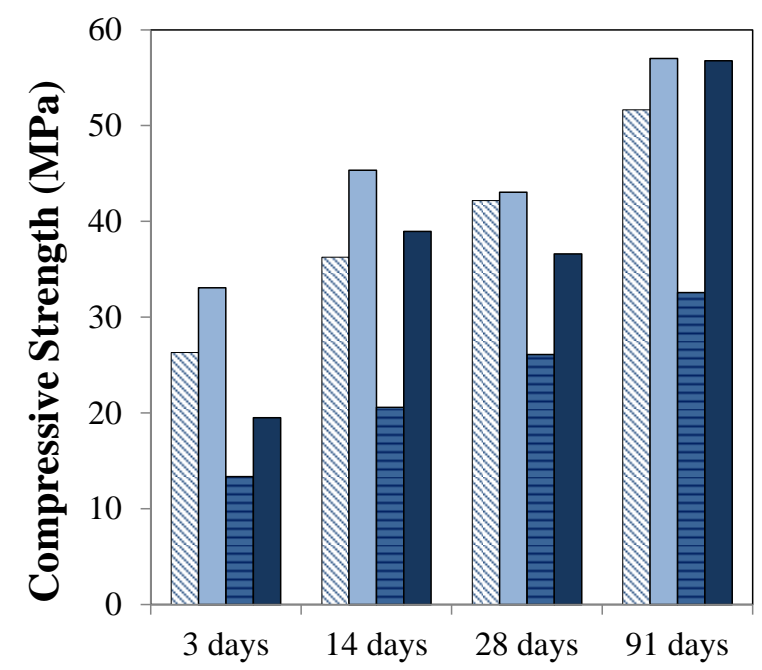

$\otimes$ Control

$\square$ Cement $+0.8 \%$ MMT

日FA+ $0.8 \% \mathrm{MMT}$

$\square \mathrm{GP}+0.8 \% \mathrm{MMT}$

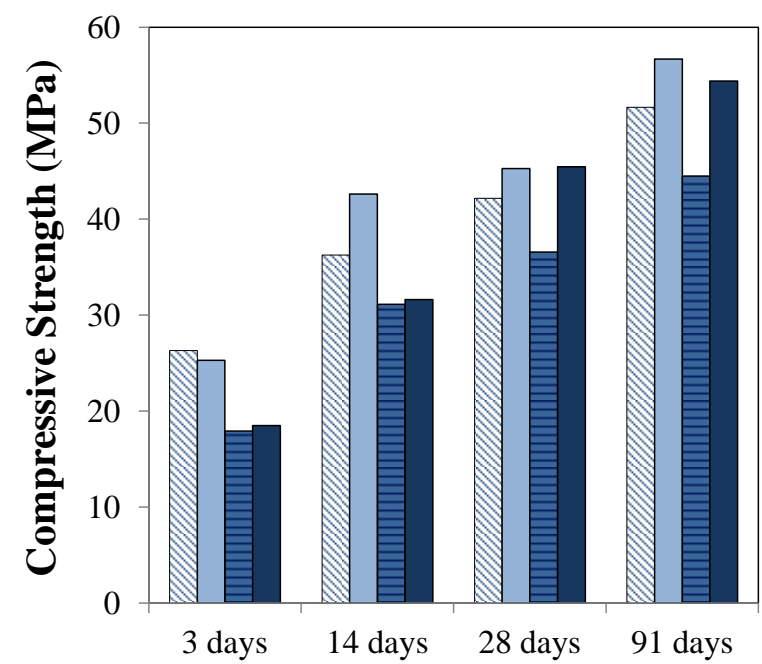

\& Control

$\square$ Cement $+0.8 \% \mathrm{TiO} 2$

$\mathrm{FA}+0.8 \% \mathrm{TiO} 2$

$\square \mathrm{GP}+0.8 \% \mathrm{TiO} 2$

Figure 2. Compressive strengths of (a) the cement pastes with MMT nanoparticles and (b) the cement pastes with $\mathrm{TiO}_{2}$ nanoparticles at various ages. 


\section{Electrical resistivity}

The electrical resistivity results of the cement pastes at 3 days, 14 days, 28 days, and 91 days of curing are presented in Figure 3a and b. It is seen from this figure that at 91 days, the addition of $\mathrm{TiO}_{2}$ nanoparticles increased the electrical resistivity of the cement pastes compared to MMT nanoparticles. It is observed that both $\mathrm{TiO}_{2}$ and MMT nanoparticles showed a similar effect on the electrical resistivity of the cement paste and the cement paste with FA at 3 days, 14 days, and 28 days. It is noted that addition of MMT nanoparticles decreased the electrical resistivity of the cement pastes compared to the control cement paste and the addition of $\mathrm{TiO}_{2}$ nanoparticles did not affect the electrical resistivity of the control cement paste at 91 days.

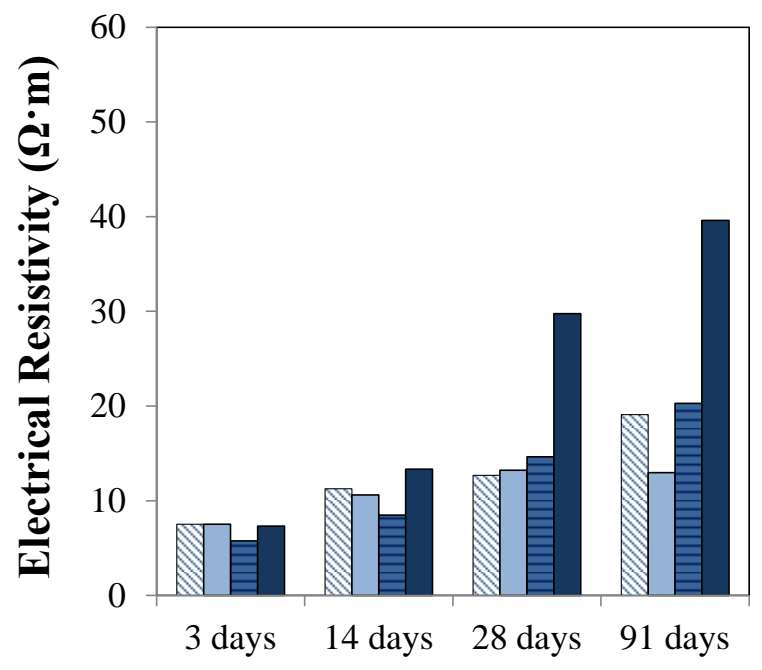

Q $\mathrm{B}$ Control

$\square$ Cement $+0.8 \%$ MMT

므 $+0.8 \% \mathrm{MMT}$

$\square \mathrm{GP}+0.8 \% \mathrm{MMT}$

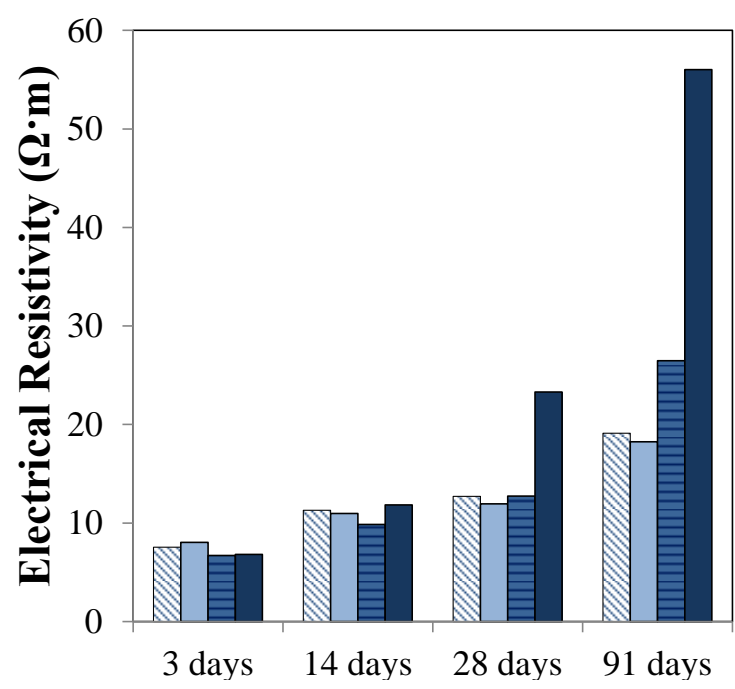

\& Control

$\square$ Cement $+0.8 \% \mathrm{TiO} 2$

$\exists \mathrm{FA}+0.8 \% \mathrm{TiO} 2$

$\square \mathrm{GP}+0.8 \% \mathrm{TiO} 2$

Figure 3. Electrical Resistivity of (a) the cement pastes with MMT nanoparticles and (b) the cement pastes with $\mathrm{TiO}_{2}$ nanoparticles at various ages. 


\section{CONCLUSION}

The effect of the $\mathrm{TiO}_{2}$ and MMT nanoparticles additions at $0.8 \%$ on the hydration, compressive strength, and electrical resistivity of cement pastes with and without GP and FA was investigated in this study. The following conclusions can be drawn from the results of this investigation:

- Both MMT and $\mathrm{TiO}_{2}$ nanoparticles were shown to have a relatively similar effect on the degree of hydration of the cement paste and cement pastes with $20 \%$ replacement of cement with GP and FA.

- It was shown that the addition of $\mathrm{TiO}_{2}$ and MMT nanoparticles improved the compressive strength of the control cement paste. It was observed that the cement paste with $\mathrm{FA}$ and $\mathrm{TiO}_{2}$ nanoparticles had a higher compressive strength than the cement paste with FA and MMT nanoparticles at all ages.

- It was observed that $\mathrm{TiO}_{2}$ nanoparticles increased the electrical resistivity of the cement paste and the cement pastes with GP and FA compared to MMT nanoparticles at 91 days.

It should be noted that a detailed microstructural and chemical analysis of the cement pastes modified with the two types of nanoparticles used in this study is required to shed light on the underlying mechanisms governing the observations made in this study. Such investigation is underway and the related results will be reported in the future publications.

\section{REFERENCES}

Aly, M. et al., 2011. Effect of nano clay particles on mechanical, thermal and physical behaviours of waste-glass cement mortars. Materials Science and Engineering: A, 528(27), pp.7991-7998.

Chang, T.-P. et al., 2007. Material properties of portland cement paste with nanomontmorillonite. Journal of Materials Science, 42(17), pp.7478-7487.

Chen, J., Kou, S. \& Poon, C., 2011. Photocatalytic cement-based materials: Comparison of nitrogen oxides and toluene removal potentials and evaluation of self-cleaning performance. Building and Environment, 46(9), pp.1827-1833.

Chen, J., Kou, S.C. \& Poon, C.S., 2012. Hydration and properties of nano-TiO 2 blended cement composites. Cement and Concrete Composites, 34(5), pp.642-649.

Chen, J. \& Poon, C.-S., 2009. Photocatalytic activity of titanium dioxide modified concrete materials - influence of utilizing recycled glass cullets as aggregates. Journal of environmental management, 90(11), pp.3436-42.

Hakamy, A., Shaikh, F.U.A. \& Low, I.M., 2015. Characteristics of nanoclay and calcined nanoclay-cement nanocomposites. Composites Part B: Engineering, 78, pp.174-184.

Hou, P. et al., 2013. Modification effects of colloidal nanoSiO2 on cement hydration and its gel property. Composites Part B: Engineering, 45(1), pp.440-448. 
Hüsken, G., Hunger, M. \& Brouwers, H.J.H., 2009. Experimental study of photocatalytic concrete products for air purification. Building and Environment, 44(12), pp.2463-2474.

Jain, J.A. \& Neithalath, N., 2010. Chloride transport in fly ash and glass powder modified concretes - Influence of test methods on microstructure. Cement and Concrete Composites, 32(2), pp.148-156.

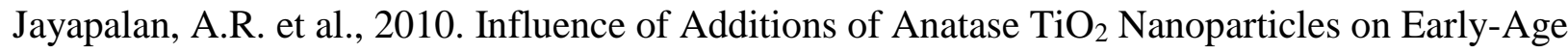
Properties of Cement-Based Materials. Transportation Research Record: Journal of the Transportation Research Board, 2141(-1), pp.41-46.

Kamali, M. \& Ghahremaninezhad, A., 2015. Effect of glass powders on the mechanical and durability properties of cementitious materials. Building and Construction Materials.

Lackhoff, M. et al., 2003. Photocatalytic activity of semiconductor-modified cement-influence of semiconductor type and cement ageing. Applied Catalysis B: Environmental, 43(3), pp.205-216.

Lee, B.Y. \& Kurtis, K.E., 2013. Effects of nano-TiO 2 on properties of cement-based materials. , 65(21).

Lee, B.Y. \& Kurtis, K.E., 2010. Influence of $\mathrm{TiO}_{2}$ nanoparticles on early C3S hydration. Journal of the American Ceramic Society, 93(10), pp.3399-3405.

Neithalath, N., Persun, J. \& Hossain, A., 2009. Hydration in high-performance cementitious systems containing vitreous calcium aluminosilicate or silica fume. Cement and Concrete Research, 39(6), pp.473-481.

Neithalath, N., Weiss, J. \& Olek, J., 2006. Characterizing Enhanced Porosity Concrete using electrical impedance to predict acoustic and hydraulic performance. Cement and Concrete Research, 36(11), pp.2074-2085.

Podsiadlo, P. et al., 2007. Ultrastrong and Stiff Layered Polymer Nanocomposites. Science, 318(October), pp.80-83.

Prasanth, R. et al., 2013. Effect of nano-clay on ionic conductivity and electrochemical properties of poly(vinylidene fluoride) based nanocomposite porous polymer membranes and their application as polymer electrolyte in lithium ion batteries. European Polymer Journal, 49(2), pp.307-318.

Sanchez, F. \& Sobolev, K., 2010. Nanotechnology in concrete - A review. Construction and Building Materials, 24(11), pp.2060-2071.

Schwarz, N., DuBois, M. \& Neithalath, N., 2007. Electrical conductivity based characterization of plain and coarse glass powder modified cement pastes. Cement and Concrete Composites, 29(9), pp.656-666. 
Shayan, A. \& Xu, A., 2006. Performance of glass powder as a pozzolanic material in concrete: A field trial on concrete slabs. Cement and Concrete Research, 36(3), pp.457-468.

Snyder, K.A. et al., 2000. Using impedance spectroscopy to assess the viability of the rapid chloride test for determining concrete conductivity. Journal of Research of the National Institute of Standards and Technology, 105(4), p.497.

Strawhecker, K.E. \& Manias, E., 2000. Structure and Properties of Poly ( vinyl alcohol )/ Na + Montmorillonite Nanocomposites., (June 1998), pp.2943-2949. 